San Jose State University

SJSU ScholarWorks

Master's Theses

Master's Theses and Graduate Research

Summer 2021

\title{
The Relationship Between Different Forms of Exercise and ADHD Symptomatology
}

Matthew A. Reynolds

San Jose State University

Follow this and additional works at: https://scholarworks.sjsu.edu/etd_theses

\section{Recommended Citation}

Reynolds, Matthew A., "The Relationship Between Different Forms of Exercise and ADHD

Symptomatology" (2021). Master's Theses. 5215.

DOI: https://doi.org/10.31979/etd.djc4-vrdc

https://scholarworks.sjsu.edu/etd_theses/5215

This Thesis is brought to you for free and open access by the Master's Theses and Graduate Research at SJSU ScholarWorks. It has been accepted for inclusion in Master's Theses by an authorized administrator of SJSU ScholarWorks. For more information, please contact scholarworks@sjsu.edu. 


\title{
THE RELATIONSHIP BETWEEN DIFFERENT FORMS OF EXERCISE AND ADHD
} SYMPTOMATOLOGY

\author{
A Thesis \\ Presented to \\ The Faculty of the Department of Psychology \\ San José State University \\ In Partial Fulfillment \\ of the Requirements for the Degree \\ Master of Arts
}

by

Matthew Reynolds

August 2021 
(C) 2021

Matthew Reynolds

ALL RIGHTS RESERVED 
The Designated Thesis Committee Approves the Thesis Titled

\title{
THE RELATIONSHIP BETWEEN DIFFERENT FORMS OF EXERCISE AND ADHD SYMPTOMATOLOGY
}

\author{
by \\ Matthew Reynolds \\ APPROVED FOR THE DEPARTMENT OF PSYCHOLOGY \\ SAN JOSÉ STATE UNIVERSITY
}

August 2021

$\begin{array}{ll}\text { Dr. Valerie Carr } & \text { Department of Psychology } \\ \text { Dr. Matthew Capriotti } & \text { Department of Psychology } \\ \text { Dr. Peggy Plato } & \text { Department of Kinesiology }\end{array}$ 


\begin{abstract}
THE RELATIONSHIP BETWEEN DIFFERENT FORMS OF EXERCISE AND ADHD SYMPTOMATOLOGY

by Matthew Reynolds
\end{abstract}

Attention deficit hyperactivity disorder (ADHD) is a neurodevelopmental disorder associated with executive function deficits as well as negative life outcomes in both childhood and adulthood. Current treatments to reduce symptoms of ADHD include stimulant medications that act as catecholamine agonists. These medications often cause undesirable side effects, to which end better understanding the effects of nonpharmacological treatments on symptoms of ADHD is critical. Research conducted in children suggests that exercise may be an effective tool for symptom reduction. However, the relationship between exercise and ADHD symptoms remains unclear for adults. The aim of this study was to address this gap in the literature by determining whether individual differences in ADHD symptoms across a broad population of young adults are related to individual differences in the amount and type of exercise in which they regularly engage. Using remote survey methods, we collected data on physical activity, physical activity type, and ADHD symptomatology. We found no significant differences in severity of ADHD symptoms as a function of exercise amount or type. Additional research using more objective, in-person measures is needed before drawing strong conclusions regarding these null findings. 


\section{ACKNOWLEDGMENTS}

I'd like to thank SJSU's Psychology department that fostered my learning and growth in science and research. Through speaking with so many professors I was able to identify a thesis topic. I knew I could immerse myself and stay motivated over the course of several years.

In particular, I'd like to thank Dr. Valerie Carr, who patiently stuck with and guided me through a seemingly never ending thesis project. For continuing to donate her time and expertise even when I was not able to give as much as I should. To say I couldn't have done this without you is a massive understatement.

I'd also like to thank my committee members, Dr. Matthew Capriotti and Dr. Peggy Plato. Along with Dr. Carr, the combinations of your expertise created a dream team that led me to think and learn in ways I couldn't imagine.

Next, I'd like to thank David Han. Your assistance with scoring and analysis is truly appreciated.

Finally, I want to thank my family and girlfriend, Sara. You all have supported me through several of the craziest years under immense pressure through the finish line. You all mean more to me than you can ever know. 


\section{TABLE OF CONTENTS}

List of Figures.....................................................................

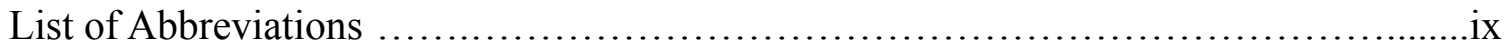

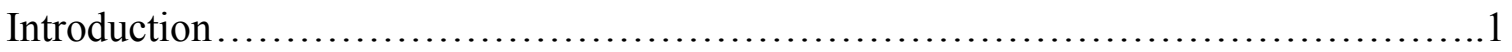

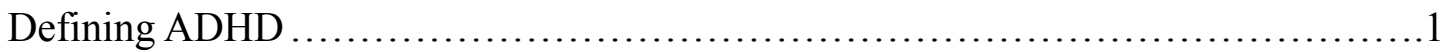

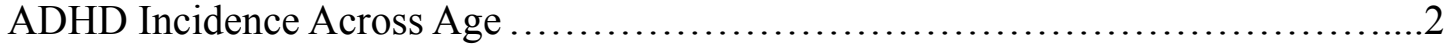

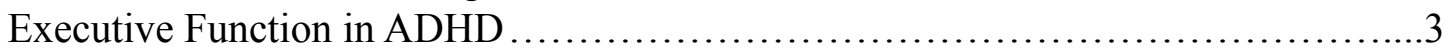

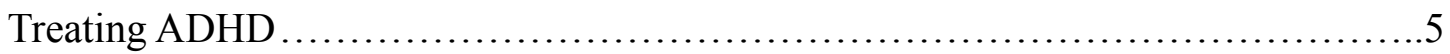

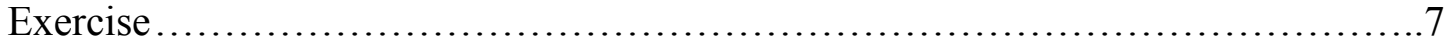

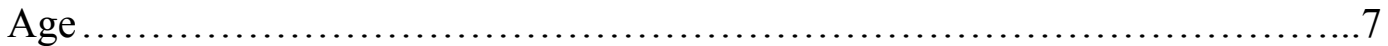

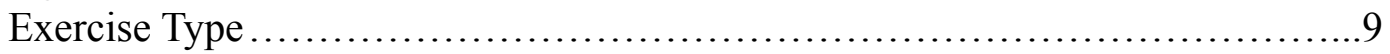

Individual Differences Across a Broad Population ............................... 10

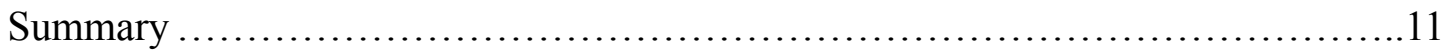

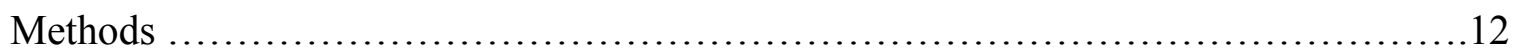

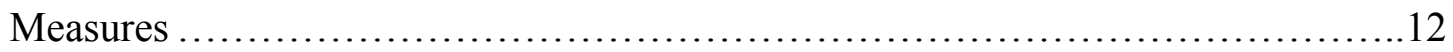

Adult ADHD Self-Report Scale (ASRS) ...................................12

International Physical Activity Questionnaire (IPAQ) ........................13

Attention Checks........................................................... 14

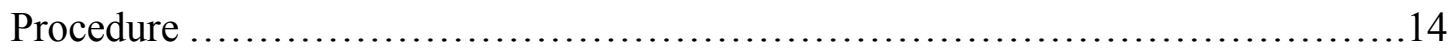

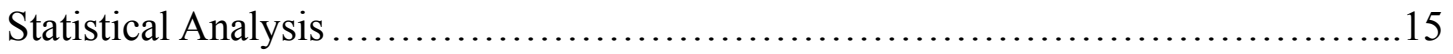

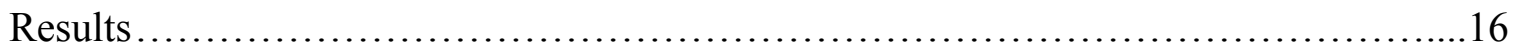

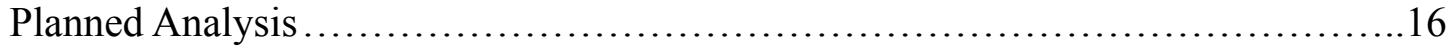

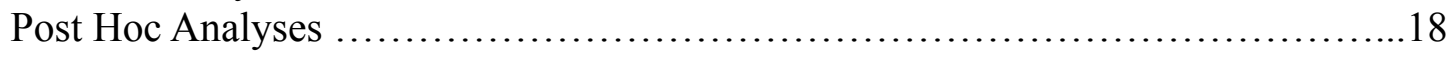

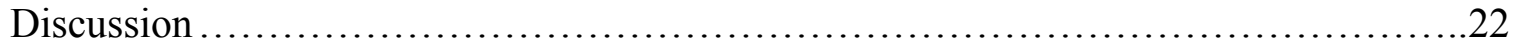

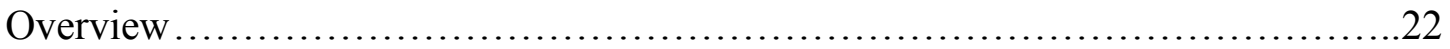



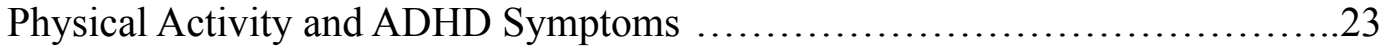

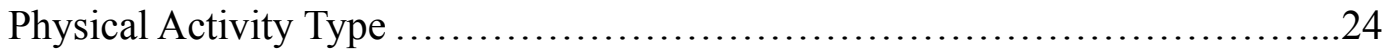

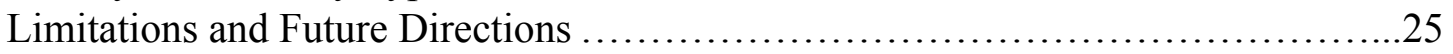

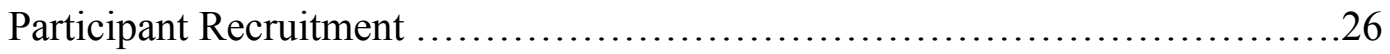

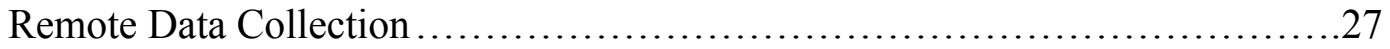

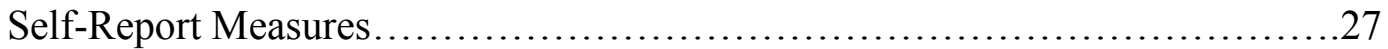

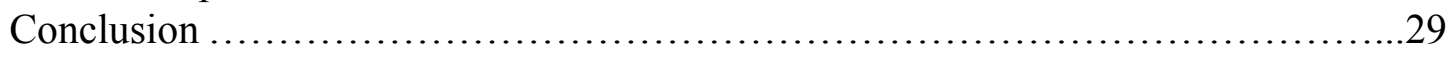

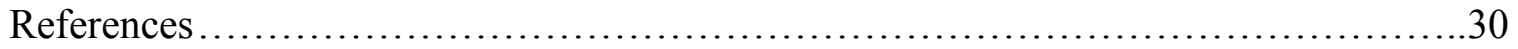




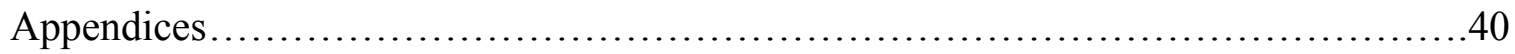

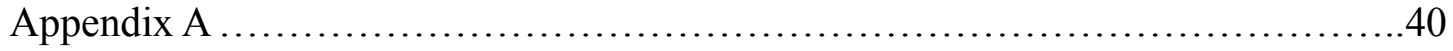

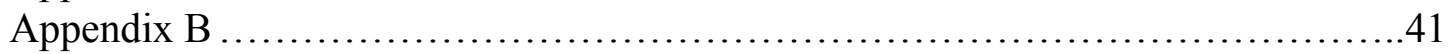




\section{LIST OF FIGURES}

Figure 1. Individual differences in ASRS total scores and IPAQ total METs.............17

Figure 2. Comparison of ASRS total scores between physical activity groups .........19

Figure 3. Relationship between physical activity type and level.....................20 


\section{LIST OF ABBREVIATIONS}

ADHD - Attention Deficit Hyperactivity Disorder WM - Working Memory

EF - Executive Function

ASRS - Adult ADHD Self-Reporting Scale

IPAQ - International Physical Activity Questionnaire

SJSU - San Jose State University 


\section{Introduction}

Attention Deficit Hyperactivity Disorder (ADHD) is a neurodevelopmental disorder most commonly identified in children by their hyperactive, inattentive, and impulsive behavior. Children with this condition often experience negative life outcomes as they struggle to learn, socialize, and adapt to the more structured world around them (Barkley, 2002; Wehmeir et al., 2010). The harm this disorder causes to society is compounded by its prevalence throughout the world's population, duration throughout the lifespan, and impact across a broad range of life outcomes (Caye et al., 2016; Wehmeir et al., 2010). Although effective pharmacological treatments for ADHD exist, these medications can cause undesirable side effects (Effron et al., 1997; Morton \& Stockton, 2000). As such, the discovery of treatment alternatives with fewer side effects is needed. Existing research suggests that exercise may be an effective tool for lessening ADHD symptoms in children, but the extent to which exercise may reduce symptoms in adults remains unclear ( Medina et al., 2010; Neudecker et al., 2019; Strong et al., 2005; Tantillo et al., 2002). As a first step in addressing this gap in the literature, we examined whether and how physical activity in a broad sample of young adults relates to ADHD symptoms.

\section{Defining ADHD}

The DSM-V describes ADHD as a persistent pattern of inattention and/or hyperactivity-impulsivity that interferes with functioning or development (American Psychiatric Association, 2013). ADHD can be further broken down into three presentations: Inattentive, Hyperactive/Impulsive, and Combined. Persons diagnosed 
with the inattentive subtype are identified by their inability to sustain attention, follow instructions, or organize their life. Those diagnosed with the hyperactive/impulsive subtype are characterized by their overabundance of energy, such that they are constantly

moving and fidgeting, in turn preventing them from engaging with more stationary tasks. Individuals diagnosed with the combined subtype show a combination of hyperactive and inattentive symptomatology (Williams et al., 2020). Though these subtypes are each associated with different behaviors, a common underlying theme is a deficit in executive function, as discussed in greater detail below.

\section{ADHD Incidence Across Age}

ADHD has been identified as one the most prevalent neurodevelopmental disorders affecting the world's population. Based on parent report data, the National Institute for Mental Health (2017) determined that 11\% of the population has received an ADHD diagnosis by a health care provider. In relation to gender, ADHD is more frequent in males than females (Gaub \& Carlson, 1997). Further, meta-analyses conducted in North America (Jensen et al., 1999) and world-wide (Polancyzk et al., 2007) found that a significant but unspecified percentage of the population displays strong symptomatology while failing to meet strict diagnostic criteria.

ADHD is commonly thought of as a childhood disorder, likely because behavioral symptoms are most noticeable in childhood when adult coping mechanisms are not yet developed (Adler et al., 2004). Further, the form of ADHD displayed often changes over time, though issues with inattention and hyperactivity remain (Millstein et al., 1997).This 
view of ADHD has driven research efforts to focus on children, deprioritizing the adult population (Wilens et al., 2009). However, a strong case can be made for giving adult ADHD the same focus and attention. For example, ADHD is prevalent in adults (Fayyad et al., 2007), and many individuals diagnosed with ADHD in adulthood did not receive a childhood diagnosis (Caye et al., 2016). However, the majority of childhood diagnoses persist into adulthood (Faraone et al., 2006). Finally, as with childhood ADHD (Currie \& Stabile, 2006; Geary et al., 2007), adult ADHD is also associated with a host of negative outcomes (Copeland et al., 2013; Gjervan et al., 2012).

\section{Executive Function in ADHD}

Executive function (EF) refers to a set of high-level cognitive processes that guide behavior towards a goal and includes processes such as planning, inhibitory control, task switching and attention shifting, decision making, and updating working memory (Banich, 2009). Though EF encompasses a wide array of cognitive processes, previous research has shown that attention shifting, planning, and inhibitory control are particularly impacted in ADHD (Martel et al., 2007; Oosterlaan et al., 2005; Willcutt et al., 2005). Indeed, efforts such as those by Brown (2009) to identify and categorize ADHD behaviors for use in a clinical setting include all three of these processes among a larger list of categories: activation (e.g. organization, time estimation, procrastination), focus (maintaining and shifting across tasks), effort (sustaining effort and energy appropriately), emotion (self-regulation of intensity), memory (temporary recall), and action (impulsivity). 
While the effects of diminished attention, planning, and inhibition are most commonly investigated in a laboratory setting, these impairments can lead to significant negative life outcomes as well. Looking first at occupational impacts, Barkley and Murphy (2010) investigated the extent to which EF deficits played a role in occupational problems using self-reported, employer-reported, and clinician-rated measures. Results showed that greater EF deficits were associated with negative occupational outcomes across all measures including self-reported occupational problems, workplace adjustment, and clinician rated occupational adjustment. A similar study by Lewandowski and associates (2008) examined academic outcomes in college students with and without an ADHD diagnosis. Students with ADHD reported greater academic concerns. In sum, these studies demonstrate how impairments in EF can be associated with day-to-day difficulties in both the workplace and classroom.

Difficulty with inhibitory control and emotional regulation may play a role in negative social outcomes in individuals with ADHD. Research has shown that these individuals have shorter romantic relationships, younger onset of sexual activity, and double the lifetime sexual partners than those without ADHD (Rokeach \& Wiener, 2018). Additionally, Michielsen and others (2015) found that individuals with ADHD were more likely to be divorced or never married, have fewer members in their family network, and experience emotional loneliness.

Lastly, EF impairments in individuals with ADHD have been associated with negative physical health outcomes as well. Deficits in inhibitory control and planning 
may increase the propensity of ADHD diagnosed individuals to engage in unhealthy, impulsive eating (Howard et al., 2010) and substance abuse. With respect to the latter, a disproportionately high percentage (11-35\%) of substance-abusing adults display ADHD symptoms (Kalbag \& Levin, 2005). Furthermore, individuals with ADHD have been shown to have a more difficult time with substance abuse treatment than controls (Dalsgaard et al., 2014; Kennedy et al., 2019).

Taken together, numerous lines of research suggest that deficits in EF are associated with negative impacts on many critical life outcomes. Treatments that help to reduce symptoms of ADHD relating to EF may, in turn, allow for improved quality of life.

\section{Treating ADHD}

The most common pharmacological treatments for ADHD are stimulants that act as catecholamine agonists. Specifically, methylphenidate (Ritalin) and dextroamphetamine (Adderall) block the reuptake of norepinephrine and dopamine in the synapse, leading to an increase in neurotransmitter presence and an associated increase in cellular signaling. Use of these medications has been shown to effectively reduce cognitive impairments in individuals with ADHD relative to controls, as well as reduce differences in brain function between these groups (Huang and Tsai, 2011; Oades et al., 2005; Pliszka, 2005; Semrud-Clikeman et al., 2008).

For example, using functional neuroimaging, Vaidya et al. (1998) compared neural activity during a test of inhibitory control in individuals with ADHD, both off and on methylphenidate, with controls. When not taking methylphenidate, the ADHD group 
exhibited less activity in the prefrontal cortex (PFC), an area critical to EF, relative to controls. While on methylphenidate, however, these differences were no longer statistically significant. Task performance results mirrored the neural results, such that controls performed significantly better than the off-medication ADHD group, whereas no group differences were found between controls and the on-medication ADHD group. These findings support the notion that systemic increases in catecholamine function are associated with improved neural function and inhibitory control. These findings have been corroborated in other studies using behavioral measures (Rhodes et al., 2006; Semrud-Clikeman et al., 2008; Wilson et al., 2006) as well as longer-term outcome measures such as quality of life and academic achievement (Huang \& Tsai, 2011).

Unfortunately, catecholamine agonizing medications have numerous side effects even with a single dose, and these side effects are exacerbated when medications are taken daily (Biederman et al., 1991; Buitelaar \& Medori, 2010). Methylphenidate users commonly report side effects including loss of appetite, insomnia, palpitations, sweating, and agitation (Levy, 1993). In an effort to find effective treatments with fewer side effects, researchers have begun to explore the utility of exercise. Findings in both animals and humans have demonstrated an increase of both norepinephrine and dopamine following exercise (Chang et al., 2011, 2012a, 2012b; Fry et al., 1994; Goodwin et al., 2008; Kraemer \& Ratamess, 2005; Kramer et al., 2006; Pratley et al., 1994; Yoon et al., 2007), leading to rapidly increasing interest in using exercise as a pharmacological alternative. 


\section{Exercise}

A substantial literature exists on the relationship between exercise and ADHD, yet uncertainty remains regarding how this relationship differs with respect to age and exercise type, as well as whether exercise may help reduce symptoms commonly associated with ADHD in the broader population.

Age

Focusing first on age, most studies investigating the efficacy of exercise in reducing ADHD symptoms have been conducted in children. For example, studies in children with ADHD demonstrate a negative correlation between exercise and psychiatric comorbidities associated with ADHD (Medina et al., 2010; Neudecker et al., 2019; Strong et al., 2005; Tantillo et al., 2002). Other studies have demonstrated improved performance on a range of executive function and attention tasks (e.g., Chang et al., 2012a; Piepmeiera et al., 2015), as well as improved academic performance (Pontifex et al., 2013). Gapin et al. (2015) conducted a review of six exercise intervention studies conducted in children and found promising improvements in cognitive processes that are typically impaired in ADHD. Similarly, a review by Archer and Kostrzewa (2012) suggested that exercise may be an effective supplemental treatment for ADHD. Research into the effects of exercise on brain structure and function have also yielded positive results in children (Berwid \& Halperin, 2012; Halperin \& Healey, 2011). A possible explanation comes from Wigal and others (2013), who posit that physiology is similarly affected by physical activity, which is known to increase catecholamine release (Jezova et 
al., 1985; Mazzeo, 1991a, 1991b; Wigal et al., 2003), and dopaminergic medication. It is important to note, however, that while substantial research on the relationship between exercise and ADHD exists for children, there have been much fewer studies conducted on adults.

Among the few studies that have been conducted in adults, Mehren et al. (2019) compared performance on a flanker task, which assesses inhibitory control, after a bout of aerobic exercise or movie viewing in adults with ADHD and healthy controls. Results indicated that adults in the ADHD group performed significantly better on the task following exercise relative to movie viewing. Similarly, Fritz \& O'Conner (2016) conducted a study on adult men with and without ADHD in which participants completed cognitive, biometric, and survey measures assessing attention, hyperactivity, mood, and motivation before and after a 20 min cycling intervention. Adults from both groups showed significantly improved mood and motivation to complete cognitive tasks after the exercise intervention. However it should be noted these effects are not related to executive function, suggesting there may be clinical utility for using exercise in ADHD populations as well. Results from both studies substantiate the growing body of evidence that aerobic exercise may have utility as an ADHD treatment method, although uncertainty remains regarding the efficacy of other forms of exercise in reducing symptoms, particularly in adults. 


\section{Exercise Type}

Much of the research examining the relationship between exercise and ADHD symptom improvement has largely focused on aerobic exercise, with a much smaller number of studies examining other forms of exercise. Field (2012) conducted a review of the utility of yoga and tai-chi on cognition in children and concluded that these activities positively benefit cognition in children with ADHD. Also focusing on children with ADHD, Pan et al. (2019) conducted a study using table tennis as a non-aerobic intervention and demonstrated positive effects on cognitive processes associated with ADHD.

The effects of resistance exercise on cognition have been evaluated in a variety of populations aside from ADHD. Specifically, studies in older adults have demonstrated improved performance on memory and EF tasks following resistance exercise interventions (Best et al., 2015; Liu-Ambrose \& Donaldson, 2009; Liu-Ambrose et al., 2010). This finding was further supported by a literature review conducted by van Uffelen and others (2008) that describes a variety of positive cognitive effects stemming from resistance exercise in older adults. The effects of resistance exercise on cognition in young adults has not been studied as frequently. One study conducted by Fortes (2018) involved a 40-week intervention in which young adult participants underwent a rigorous resistance exercise regimen and were periodically tested on the Stroop task, which assesses inhibitory control. Results indicated a significant improvement in task performance when resistance exercise was completed in higher volumes (i.e., more sets). 
While this study suggests a promising relationship between resistance exercise and EF performance, additional research in adults is needed.

Studies examining the effects of exercise interventions on symptoms of ADHD have utilized interventions of varying duration. Most studies have used acute interventions and have shown promising effects on EF in both general and ADHD populations (Chang et al., 2011, 2012a, 2012b). Long-term interventions have been investigated less extensively, but have also provided promising results with respect to EF and various forms of memory (Best et al., 2015; Chang, 2014; Liu-Ambrose et al., 2015). More research needs to be conducted directly comparing interventions of different duration to determine the relative utility of each.

Taken together, studies of exercise and ADHD symptomatology suggest that aerobic exercise is an effective alternative to, or supplement for, pharmacological treatment. However, non-aerobic physical activity such as resistance exercise has not received the same attention as aerobic exercise. Given promising results in other populations, especially with respect to EF, it is possible that resistance exercise may benefit forms of cognition affected in ADHD as well.

\section{Individual Differences Across a Broad Population}

As noted earlier, a significant but unspecified percentage of the world population displays symptoms of ADHD but fails to meet the strict diagnostic criteria for the disorder (Jensen et al., 1999; Polanczyk et al., 2007). It is thus possible that exercise may prove similarly helpful in reducing symptoms associated with ADHD in a broad 
population. However, research exploring the relationship between individual differences in physical activity and individual differences in ADHD symptom severity across a broad adult population is lacking.

\section{Summary}

Although significant research has been conducted regarding the efficacy of pharmacological treatments in reducing symptoms of ADHD, non-aerobic exercise as a non-medication alternative has been largely neglected, particularly in adult populations. Additionally, few studies examining the relationship between physical activity and ADHD symptoms have taken into account whether this relationship may differ for different forms of exercise, such as aerobic and resistance exercise. This study aimed to address these gaps in the literature by examining whether individual differences in self-reported physical activity levels among a broad population of young adults relate to individual differences in ADHD symptoms, while taking into account type of exercise. We hypothesized that individuals engaging in more physical activity would report less severe ADHD symptomatology, and that this negative relationship would hold true regardless of exercise type. 


\section{Methods}

A total of 219 adults (aged 18-35 years, $\mathrm{M}=22.44, \mathrm{SD}=5.43 ; 139$ women, 79 men, 1 non-binary) were recruited from San Jose State University's Sona participant pool ( $\mathrm{N}=$ 155) as well as Amazon Mechanical Turk $(\mathrm{N}=64)$. Data were collected in the spring through the fall of 2019. All participants were fluent English speakers and self-reported that they were free from psychiatric and neurological conditions aside from ADHD. Participants were excluded from analysis if they failed to complete all portions of the survey or failed attention checks included in the survey.

Participants recruited through the SJSU Sona system were compensated with extra credit or class credit as dictated by their instructors, and participants recruited through Mechanical Turk were compensated with \$3.00 USD. Informed consent was obtained from all participants in a manner approved by the San Jose State University Institutional Review Board.

\section{Measures}

\section{Adult ADHD Self-Report Scale (ASRS)}

To assess ADHD symptomatology, participants completed the Adult ADHD Self-Report Scale (ASRS; Kessler et al., 2005). This scale has been validated to reliably predict symptoms associated with ADHD. The ASRS uses a series of 18 self-report questions (see Appendix A) asking about the frequency of subjects' attention-related difficulties over the past 6 months. Response options are placed on a 5-point Likert scale ranging from 'never' to 'very often,' and an overall score ranging from 18 to 90 is tallied 
based on the participant's responses. Previous research assessing the validity and reliability of the ASRS has demonstrated that the initial six questions are most effective at categorizing ADHD symptomatology (Kessler et al., 2005), whereas the subsequent 12 questions can provide insight into the depth and degree of impairment. For the purposes of this study, responses to all 18 questions were used to calculate a total ASRS score.

\section{International Physical Activity Questionnaire (IPAQ)}

The International Physical Activity Questionnaire-Long Form (IPAQ; Hagstromer et al., 2006) is a self-report measure that assesses the frequency and intensity with which participants engage in a variety of physical activities. To score the measure, this frequency and intensity information was converted into metabolic equivalent task (MET) units, which reflect the ratio of the rate of energy expended during a task to that expended at rest. The scoring process began with data cleaning. For each type of task (e.g., vigorous activity at work), the task's duration was capped at a maximum of 180 minutes. Additionally, participants who reported engaging in more than $16 \mathrm{hrs}$ of physical activity within a single day across all physical tasks were considered outliers and removed from analysis. Subsequent to data cleaning, we applied a multiplier to participants' MET minutes based on the intensity of the task (i.e. walking tasks $x 3.3$, moderate tasks $x 4$, and vigorous tasks $\mathrm{x}$ 8). A participant's total METs were calculated by adding together the subsequent values for walking, moderate, and vigorous tasks. In the end, a given participant's IPAQ score reflects the total number of MET minutes per week across all physical activity types. 
Given our interest in exercise type, we modified the IPAQ to include a small set of additional questions enabling us to categorize different types of activity as being more similar to aerobic exercise or resistance exercise (see Appendix B for this modified version). For a given activity, we asked whether participants experienced respiratory fatigue (more indicative of aerobic exercise), muscle fatigue (more indicative of resistance exercise), or neither. METs for each exercise type were totalled across all activities. Participants with greater aerobic than resistance METs were classified into the Aerobic group, and those with greater resistance than aerobic METs were classified into the Resistance group. Participants who did not report experiencing respiratory or muscle fatigue were not assigned to one of these categories and were not included in analyses focusing on physical activity type.

\section{Attention Checks}

To help reduce concerns regarding data quality in online studies, we included a total of four attention checks: two embedded in the ASRS, and two embedded in the IPAQ. These checks instructed participants to check a pre-selected response and were designed to identify participants who are not paying sufficient attention to the survey. Participants failing one or more attention checks were excluded from analysis (see Results).

\section{Procedure}

All participants completed the study online via Qualtrics, a platform for performing survey-based research (Provo, Utah). After providing consent, participants answered demographic questions and then completed the ASRS followed by the modified IPAQ. 
Once finished with the study, they were directed back to the relevant recruitment platform to receive credit or compensation, as appropriate. In total, completing the questionnaires lasted between 15 and 20 minutes.

\section{Statistical Analysis}

To assess the relationship between ADHD symptomatology and physical activity, we planned to conduct a multiple linear regression analysis using the ASRS total score as the dependent variable and total METs and physical activity type as independent variables. However, as described below, the total METs data were positively skewed, such that variability in this measure was limited and very few participants demonstrated high levels of activity. Accordingly, we instead conducted a series of post hoc analyses in which participants's total MET values were used to classify them into either a Low or High physical activity group using a median split of the data. 


\section{Results}

From the original sample of 219 participants, 17 failed to complete all portions of the survey, 5 failed attention checks included in the survey, and 21 participants were removed as outliers with respect to IPAQ total METs. As such, data from 176 participants were used in our statistical analyses (aged 18-35 years, $\mathrm{M}=22.88, \mathrm{SD}=5.91 ; 109$ women, 66 men, 1 non-binary).

\section{Planned Analysis}

To assess the relationship between individual differences in the severity of ADHD symptoms and individual differences in physical activity levels, we first examined the distribution of scores calculated from the ASRS (total score) and IPAQ (total METs), respectively. As can be seen in Figure 1, although ASRS total scores were normally distributed, total METs were positively skewed, such that a large proportion of participants did not regularly engage in physical activity. This lack of variability was inappropriate for our planned analysis, leading us to instead perform a series of alternative post hoc analyses. 


\section{Figure 1}

Individual differences in ASRS total scores and IPAQ total METS
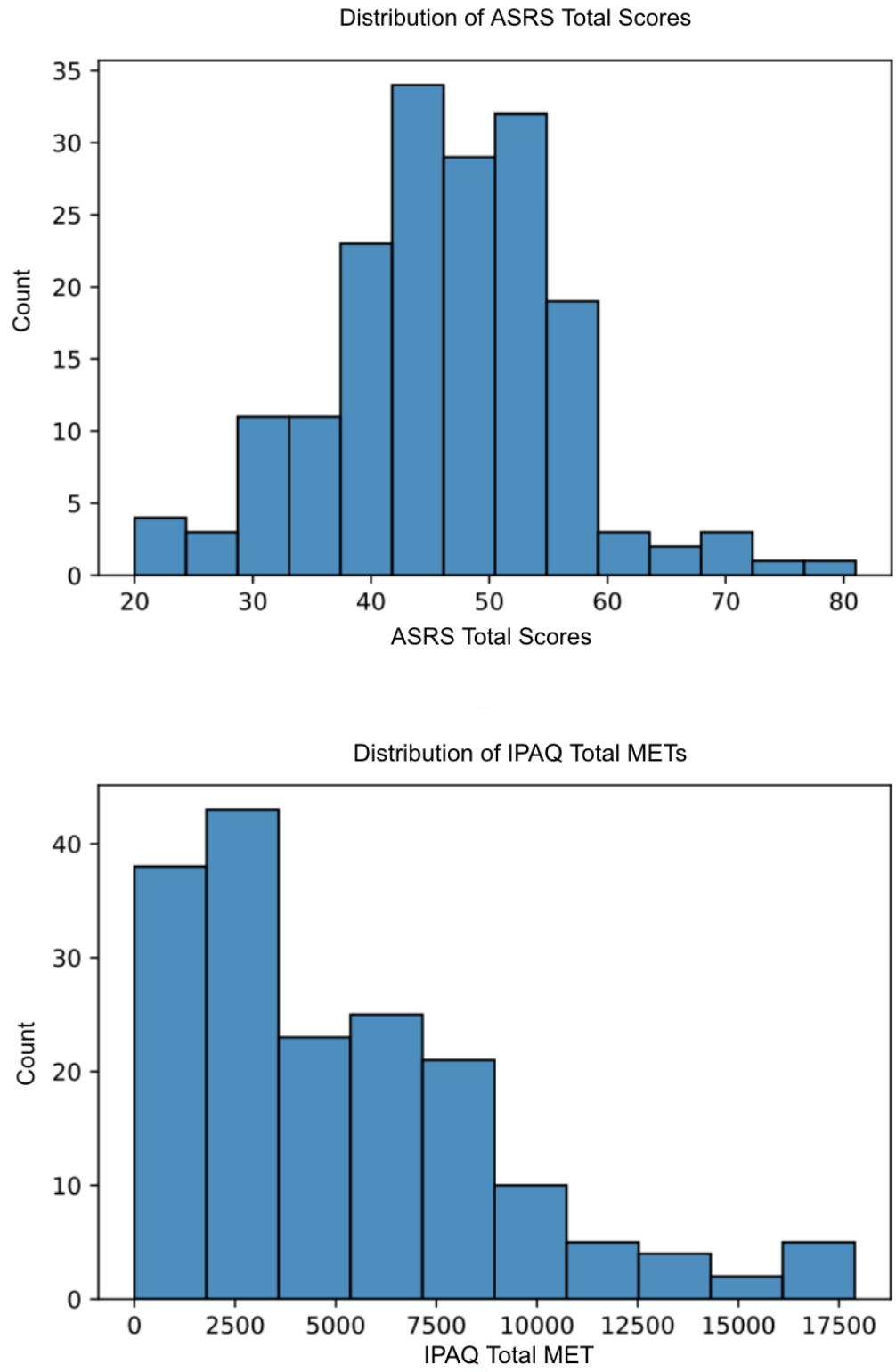

Note. Histograms showing the distribution of ASRS total scores (above) and IPAQ total METs (below). ASRS: Adult ADHD Self-Report Scale, IPAQ: International Physical Activity Questionnaire, MET: metabolic equivalent task. 


\section{Post Hoc Analyses}

Rather than examine IPAQ total METs as a continuous measure as originally planned, we instead performed a median split of total MET values, allowing us to classify participants as belonging to either a Low or High physical activity group. We then performed two analyses, the first of which included data from all usable participants $(\mathrm{n}=$ 176), and the second included data from a subset of usable participants $(n=75)$ who could be classified as belonging to either the Aerobic or Resistance group.

First, using data from all participants, we conducted an independent samples t-test to compare ASRS total scores in the Low $(\mathrm{n}=88)$ and High $(\mathrm{n}=88)$ physical activity groups. Results indicated that there was not a significant difference in ASRS scores between the Low $(M=45.51, S D=10.85)$ and High $(M=47.17, S D=8.93)$ median split physical activity groups, $t(174)=-1.11, p=.26$. See Figure 2 . 


\section{Figure 2}

Comparison of ASRS total scores between physical activity groups

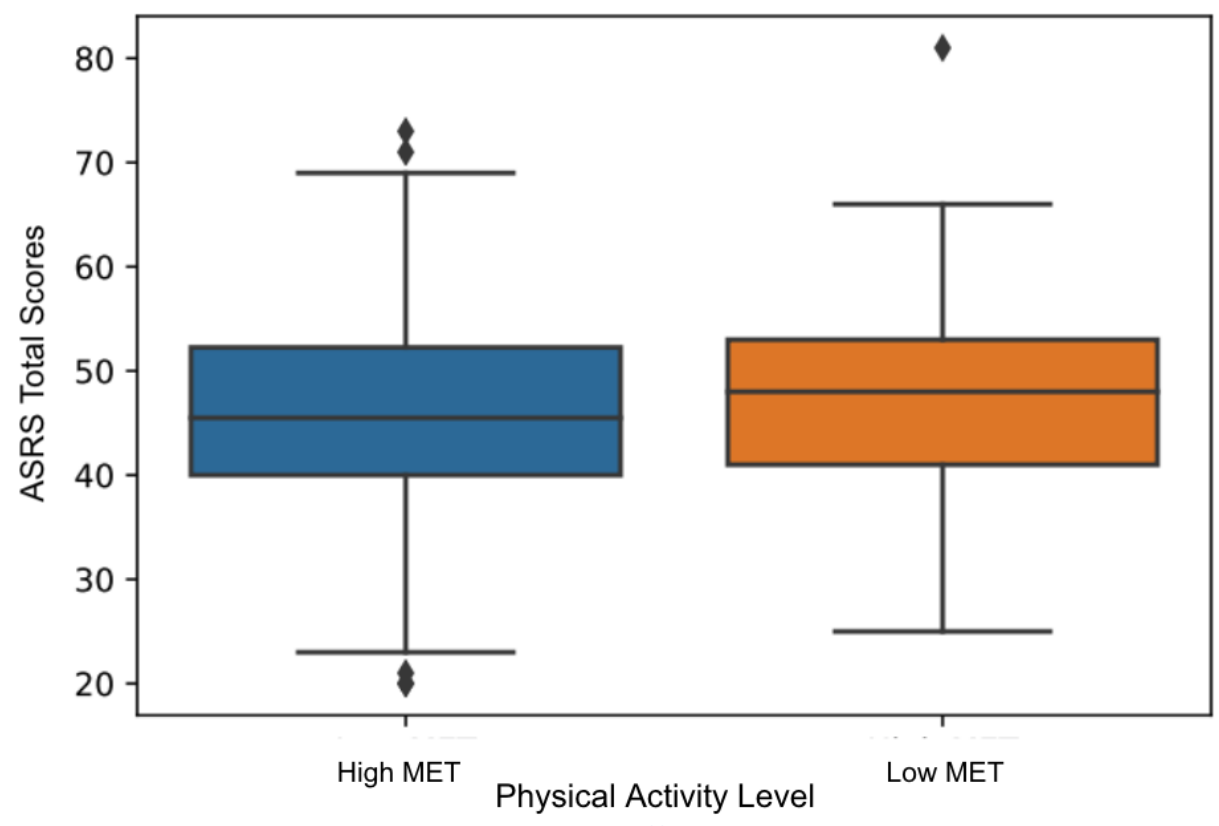

Note. Box and whisker plots illustrating a non-significant difference between physical activity groups. Whiskers represent 1.5 times the interquartile range extending from the lower and upper bounds of the box. ASRS: Adult ADHD Self Report Scale, MET: metabolic equivalent task.

Next, using a subset of participants belonging to the Aerobic $(n=44)$ or Resistance $(n$ $=31$ ) groups, we performed a two-way analysis of variance to evaluate the influence of physical activity type (Aerobic, Resistance) and physical activity level (Low, High) on ASRS total scores. Results indicated that there was no significant main effect of activity 
type, $F(1,71)=.05, p=.82$, and no significant main effect of activity level, $F(1,71)$

$=1.03, p=.31$. Finally, there was not a significant interaction between physical activity type and level, $F(1,71)=.23, p=.62$. See Figure 3 .

\section{Figure 3}

Relationship between physical activity type and level

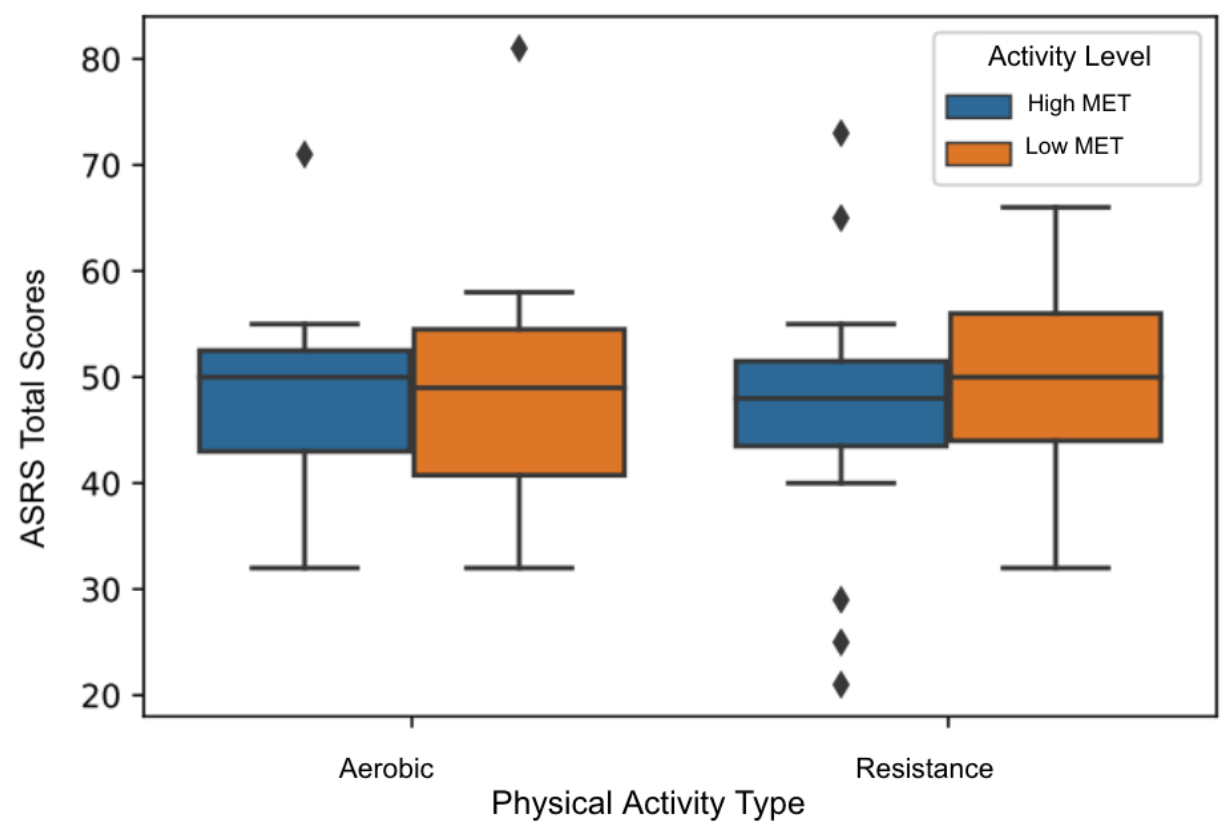

Note. Box and whisker plots illustrating the relationship between ASRS total score and physical activity type and level. Whiskers represent 1.5 times the interquartile range extending from the lower and upper bounds of the box. ASRS: Adult ADHD Self Report Scale, MET: metabolic equivalent task. 
Finally, we repeated both of the above analyses excluding outliers, who were identified as scoring three standard deviations above or below the mean on each relevant measure. The analyses in which outliers were excluded did not change the overall findings, such that all results remained non-significant. 


\section{Discussion}

\section{Overview}

This study investigated the relationship between physical activity and symptoms of ADHD in a large population of young adults. Given that the physical activity data were positively skewed and lacked variability, we conducted a series of post hoc analyses in place of our planned regression analysis. Specifically, we examined whether participants who engaged in high amounts of physical activity had lower ASRS total scores than those who engaged in low amounts of physical activity. For a subset of participants who could be classified as primarily engaging in either aerobic exercise or resistance exercise, we further examined whether ASRS total scores differed as a function of physical activity type and amount. Results indicated that ADHD symptom severity did not significantly differ according to physical activity type, physical activity amount, or an interaction between the two.

\section{Comparison to Prior Literature}

Contrary to our hypothesis that individuals who engage in greater amounts of exercise would report fewer symptoms of ADHD, we found no significant difference in ASRS total scores between the Low and High physical activity groups. This hypothesis was based on prior studies suggesting beneficial effects of physical activity on ADHD symptoms. Potential reasons for our discrepant findings are discussed below. 


\section{Physical Activity and ADHD Symptoms}

To the best of our knowledge, no prior studies have examined the relationship between physical activity and symptoms of ADHD in a broad population. Rather, the vast majority of studies examining this relationship have been conducted in individuals with an ADHD diagnosis. Furthermore, most such studies have been conducted in children with ADHD, with significantly less research conducted in adults. Our choice of population likely contributed to differences between the current results and those of prior studies that have demonstrated beneficial effects of exercising on symptoms of ADHD.

Reviews of the literature pertaining to children with ADHD have concluded that exercise is an effective supplemental treatment for ADHD (Archer \& Kostrzewa, 2012) and improves cognitive processes typically impaired in ADHD (Gapin, 2015). Other studies have shown improved performance in children with ADHD on EF and attention tasks following exercise (Chang et al., 2012; Piepmeiera et al., 2015), as well as a negative correlation between exercise and psychiatric comorbidities associated with ADHD (Medina et al., 2010; Strong et al., 2005; Tantillo et al., 2002)

ADHD is commonly thought of as a childhood disorder due to its salient symptomatology in children relative to adults. Research suggests that adults with ADHD may learn coping strategies that lessen symptoms experienced in childhood (Young, 2005). With respect to the current study, one explanation for our lack of significant findings is that the coping strategies used by adults to manage symptoms of ADHD are mitigating the potential benefits exercise might otherwise provide. In the future, 
researchers should consider asking participants about their use of such strategies to better understand this interesting dynamic.

Another methodological difference between the current study and prior research is that we recruited a broad population of young adults rather than specifically targeting individuals with ADHD. Although there was a reasonable amount of variability with respect to ASRS total score across participants, our sample nonetheless contained very few individuals with high scores. Specifically, only 2 of the 176 participants analyzed met ADHD criteria according to the ASRS scoring system. The lack of strong ADHD symptoms in our sample may have made it difficult to detect differences in symptom severity across individuals who engage in low and high amounts of physical activity.

\section{Physical Activity Type}

We hypothesized that, regardless of exercise type, individuals engaging in regular physical activity would have fewer ADHD symptoms than those who are sedentary. Results did not support this hypothesis, such that ASRS total scores did not significantly differ according to activity level - a finding that was true for both types of activity. Thus, our results do not align with prior studies suggesting that both aerobic and non-aerobic forms of physical activity can be beneficial for reducing symptoms of
ADHD.
Most studies demonstrating the benefits of exercise for reducing symptoms of ADHD have focused on aerobic exercise (Chang et al., 2016; Fritz \& O’Conner, 2016; Mehren et al., 2019), and the same is true for studies showing the beneficial effects of exercise on 
EF processes (Chang et al., 2012a, 2012b; Coles \& Tomporowski, 2008). A smaller number of studies have shown that forms of non-aerobic exercise, such as yoga (Field, 2012) and table-tennis (Pan et al., 2015), also benefit cognition in individuals with ADHD.

With respect to resistance exercise, specifically, to the best of our knowledge no studies have examined the relationship between resistance exercise and symptoms of ADHD. However, a relatively large literature exists relating to resistance exercise and cognition in non-ADHD populations such as older adults. Studies found positive effects of resistance exercise interventions in older adults on EF (Chang, 2012; Liu-Ambrose \& Donaldson, 2009; Liu-Ambrose et al., 2010). The cognitive benefits reported in these studies may be particularly apparent given that cognition declines in older adulthood; in other words, there may be more room for improvement in older adult populations relative to the younger adult population used in the current study. Additionally, although the ASRS includes questions that relate to EF processes such as inhibitory control, the survey is not designed to test EF, specifically. Future researchers should consider including a test of $E F$ to determine whether and how different types of exercise impact performance.

\section{Limitations and Future Directions}

The results of this study may have been affected by several methodological limitations associated with participant recruitment, remote data collection, and use of self-report measures. 


\section{Participant Recruitment}

As can be seen in Figure 1, the distribution of total MET values obtained from the IPAQ was positively skewed such that most participants engaged in very little physical activity. This lack of variability suggests that our two participant pools, SJSU's Sona system and Amazon's Mechanical Turk, were not sufficiently diverse with respect to exercise habits to perform our planned analysis. Advertising at gyms and fitness centers could better target those who regularly exercise. Furthermore, ads could be targeted towards gym users enrolled in specific types of classes such as spin vs. body sculpting to increase the likelihood of recruiting a large number of individuals who participate in either aerobic or resistance training, respectively.

As already noted above, although there was a reasonable amount of variability in ASRS total scores, nonetheless very few participants exhibited scores on the higher end of the scale. To increase the number of participants experiencing more severe symptoms of ADHD, designing recruitment flyers that specifically mention the researchers' interest in studying individuals with ADHD may be helpful, as would posting flyers in accessible education centers on campus and/or ADHD clinics that provide assessment and treatment services . Future studies may also consider including additional psychiatric screeners, such as anxiety or depression screeners, to more effectively exclude participants with non-ADHD disorders and increase confidence that the symptomatology is due to ADHD and not similar, often comorbid disorders. 


\section{Remote Data Collection}

Online studies have both advantages and disadvantages when compared to studies conducted in person. Online studies enable rapid data collection, typically result in larger sample sizes (Sassenberg \& Dietrich, 2019), and are capable of reaching a wider diversity of participants than is found on most college campuses. A major disadvantage of online studies is their lack of laboratory control. For example, we cannot guarantee that participants completed the study in a quiet location while attending fully to the study content. In an attempt to reduce concerns regarding a lack of attention, we included a series of checks throughout the IPAQ and ASRS surveys and removed participants who failed them from analysis. Subsequent to the pandemic, when conducting in-person research can be completed safely, future investigations should address the aforementioned limitations by conducting in-person research, which would have the added bonus of allowing for more objective assessments of physical fitness and ADHD symptomatology, as discussed below.

\section{Self-Report Measures}

We relied upon self-report measures for determining the severity of ADHD symptoms as well as the amount and type of physical activity in which participants engaged. While both the IPAQ and ASRS are validated measures that are frequently used in the literature, they nonetheless have limitations that may have affected our results and our ability to draw meaningful conclusions from these findings. 
The IPAQ is a self-report measure that asks participants to provide details regarding the frequency and duration with which they engage in a variety of physical activities. Participants may have exaggerated or over-estimated their exercise habits given that self-report measures of health have been shown to reflect a social desirability bias (Klesges et al., 2004; Van de Mortel, 2008; Widmar et al., 2016). Once in-person data collection is allowed again, researchers should consider using a step test or walking test that would allow for an objective measure of participants' fitness.

Also with respect to the IPAQ, we utilized a modified version that included newly developed questions designed to determine whether the type of physical activity in which participants engaged was more similar to aerobic or resistance exercise. This novel language has not been validated. For example, using the phrase "respiratory exhaustion" as an indicator of aerobic exercise may have led participants to under-report their aerobic activity. Thus, additional research is needed to determine whether the answers to these questions correlate with objective measures of aerobic fitness and strength.

Finally, with respect to measures of ADHD symptomatology, future researchers should consider using a clinical interview such as the Adult ADHD Clinical Diagnostic Scale (ACDS). A more objective measure of adult ADHD symptomatology could circumvent issues associated with self-report such as bias and individual interpretation, offering greater validity and reliability, although at a cost of convenience. The ACDS and similar measures could still be conducted online allowing easier reach to a more broad population. 


\section{Conclusion}

This study set out to investigate the relationship between exercise and ADHD symptomatology with two goals. First, we aimed to understand whether higher levels of physical activity were associated with lower ADHD symptomatology in a broad population of young adults. Second, we aimed to understand whether this relationship held true for both aerobic and resistance exercise. Results of this study concluded that participants' symptom severity did not differ as a function of either their level of physical activity or type of physical activity. Before making strong conclusions regarding these null findings, several methodological limitations should be taken into consideration and improved upon in future studies. Namely, data were collected online using self-report measures, there were few participants with high levels of ADHD symptoms, and there was a lack of variability in the amount of physical activity. Also, the use of a non-experimental design precluded our ability to explore a causal relationship between physical activity and symptoms of ADHD. Additional research that utilizes in-person and more objective measures of physical fitness and ADHD symptomatology will help to better uncover whether and how exercise and ADHD symptoms are related in an adult population. 


\section{References}

Adler, L. A. (2004). Clinical presentations of adult patients with ADHD. Journal of Clinical Psychiatry, 65, 8-11.

American Psychiatric Association. (2013). Diagnostic and Statistical Manual of Mental Disorders $\left(5^{\text {th }}\right.$ ed.). Washington DC Author

Archer, T., \& Kostrzewa, R. M. (2012). Physical exercise alleviates ADHD symptoms: regional deficits and development trajectory. Neurotoxicity Research, 21(2), 195-209. https://doi.org/10.1007/s12640-011-9260-0

Banich, M. T. (2009). Executive function: The search for an integrated account. Current Directions in Psychological Science, 18(2), 89-94. https://doi.org/10.1111/j.1467-8721.2009.01615.x

Barkley, R. A. (2002). Major life activity and health outcomes associated with attention-deficit/hyperactivity disorder. Journal of Clinical Psychiatry, 63, 10-15.

Barkley, R. A., \& Murphy, K. R. (2010). Impairment in occupational functioning and adult ADHD: the predictive utility of executive function (EF) ratings versus EF tests. Archives of Clinical Neuropsychology, 25(3), 157-173. https://doi.org/10.1093/arclin/acq014

Best, J. R., Chiu, B. K., Hsu, C. L., Nagamatsu, L. S., \& Liu-Ambrose, T. (2015). Long-term effects of resistance exercise training on cognition and brain volume in older women: results from a randomized controlled trial. Journal of the International Neuropsychological Society, 21(10), 745-756. https://doi.org/10.1017/S1355617715000673

Berwid, O. G., \& Halperin, J. M. (2012). Emerging support for a role of exercise in attention-deficit/hyperactivity disorder intervention planning. Current Psychiatry Reports, 14(5), 543-551. https://doi.org/10.1007/s11920-012-0297-4

Biederman, J., Newcorn, J., \& Sprich, S. (1991). Comorbidity of attention deficit hyperactivity disorder. The American Journal of Psychiatry, 148(5), 564-577. https://oi.org/10.1176/ajp.148.5.564

Brown, T. E. (2009). ADD/ADHD and impaired executive function in clinical practice. Current Attention Disorders Reports, 1(1), 37-41. https://doi.org/10.1007/s11920-008-0065-7

Buitelaar, J., \& Medori, R. (2010). Treating attention-deficit/hyperactivity disorder beyond symptom control alone in children and adolescents: a review of the 
potential benefits of long-acting stimulants. European Child \& Adolescent Psychiatry, 19(4), 325-340. https://doi.org/10.1007/s00787-009-0056-1

Caye, A., Swanson, J., Thapar, A., Sibley, M., Arseneault, L., Hechtman, L., ... \& Rohde, L. A. (2016). Life span studies of ADHD - conceptual challenges and predictors of persistence and outcome. Current Psychiatry Reports, 18(12), 1-11. https://doi.org/10.1007/s11920-016-0750-x

Caye, A., Rocha, T. B. M., Anselmi, L., Murray, J., Menezes, A. M., Barros, F. C., ... \& Swanson, J. M. (2016). Attention-deficit/hyperactivity disorder trajectories from childhood to young adulthood: evidence from a birth cohort supporting a late-onset syndrome. JAMA psychiatry, 73(7), 705-712. https://doi:10.1001/jamapsychiatry.2016.0383

Chang, Y. K., Tsai, C. L., Hung, T. M., So, E. C., Chen, F. T., \& Etnier, J. L. (2011). Effects of acute exercise on executive function: a study with a Tower of London Task. Journal of Sport and Exercise Psychology, 33(6), 847-865. https://doi.org/10.1123/isep.33.6.847

Chang, Y. K., Labban, J. D., Gapin, J. I., \& Etnier, J. L. (2012a). The effects of acute exercise on cognitive performance: a meta-analysis. Brain Research, 1453, 87-101. https://doi.org/10.1016/j.brainres.2012.02.068

Chang, Y. K., Liu, S., Yu, H. H., \& Lee, Y. H. (2012b). Effect of acute exercise on executive function in children with attention deficit hyperactivity disorder. Archives of Clinical Neuropsychology, 27(2), 225-237. https://doi.org/10.1093/arclin/acr094

Chang, Y. K., Pan, C. Y., Chen, F. T., Tsai, C. L., \& Huang, C. C. (2012c). Effect of resistance-exercise training on cognitive function in healthy older adults: a review. Journal of Aging and Physical Activity, 20(4), 497-517. https://doi.org/10.1123/japa.20.4.497

Chang, Y. K., Hung, C. L., Huang, C. J., Hatfield, B. D., \& Hung, T. M. (2014). Effects of an aquatic exercise program on inhibitory control in children with ADHD: a preliminary study. Archives of Clinical Neuropsychology, 29(3), 217-223. https://doi.org/10.1093/arclin/acu003

Coles, K., \& Tomporowski, P. D. (2008). Effects of acute exercise on executive processing, short-term and long-term memory. Journal of Sports Sciences, 26(3), 333-344. https://doi.org/10.1080/02640410701591417

Copeland, W. E., Adair, C. E., Smetanin, P., Stiff, D., Briante, C., Colman, I., ... \& Angold, A. (2013). Diagnostic transitions from childhood to adolescence to early 
adulthood. Journal of Child Psychology and Psychiatry, 54(7), 791-799. https://doi.org/10.1111/jepp.12062

Currie, J., \& Stabile, M. (2006). Child mental health and human capital accumulation: the case of ADHD. Journal of Health Economics, 25(6), 1094-1118. https://doi.org/10.1016/j.jhealeco.2006.03.001

Dalsgaard, S., Mortensen, P. B., Frydenberg, M., \& Thomsen, P. H. (2014). ADHD, stimulant treatment in childhood and subsequent substance abuse in adulthood-a naturalistic long-term follow-up study. Addictive Behaviors, 39(1), 325-328. https://doi.org/10.1016/j.addbeh.2013.09.002

Efron, D., Jarman, F., \& Barker, M. (1997). Side effects of methylphenidate and dexamphetamine in children with attention deficit hyperactivity disorder: a double-blind, crossover trial. Pediatrics, 100(4), 662-666. https://doi.org/10.1542/peds.100.4.662

Faraone, S. V., Biederman, J., \& Mick, E. (2006). The age-dependent decline of attention deficit hyperactivity disorder: a meta-analysis of follow-up studies. Psychological Medicine, 36(2), 159. https://doi.org/10.1017/S003329170500471X

Fayyad, J., De Graaf, R., Kessler, R., Alonso, J., Angermeyer, M., Demyttenaere, K., ... \& Lépine, J. P. (2007). Cross-national prevalence and correlates of adult attention-deficit hyperactivity disorder. The British Journal of Psychiatry, 190(5), 402-409. https://doi.org/10.1192/bip.bp.106.034389

Field, T. (2012). Exercise research on children and adolescents. Complementary Therapies in Clinical Practice, 18(1), 54-59. https://doi.org/10.1016/i.ctcp.2011.04.002

Fortes, L. D. S., Costa, M. D. C., Perrier-Melo, R. J., Brito-Gomes, J. L., Nascimento-Júnior, J. R. A., de Lima-Júnior, D. R. A. A., \& Cyrino, E. S. (2018). Effect of volume in resistance training on inhibitory control in young adults: a randomized and crossover investigation. Frontiers in Psychology, 9, 2028. https://doi.org/10.3389/fpsyg.2018.02028

Fritz, K. M., \& O'Connor, P. J. (2016). Acute Exercise Improves Mood and Motivation in Young Men with ADHD Symptoms. Medicine and Science in Sports and Exercise, 48(6), 1153-1160. https://doi.org/10.1249/mss.0000000000000864

Fry, A. C., Kraemer, W. J., Van Borselen, F., Lynch, J. M., Triplett, N. T., Koziris, L. P., \& Fleck, S. J. (1994). Catecholamine responses to short-term high-intensity resistance exercise overtraining. Journal of Applied Physiology, 77(2), 941-946. https://doi.org/10.1152/jappl.1994.77.2.941 
Gaub, M., \& Carlson, C. L. (1997). Gender differences in ADHD: a meta-analysis and critical review. Journal of the American Academy of Child \& Adolescent Psychiatry, 36(8), 1036-1045. https://doi.org/10.1097/00004583-199708000-00011

Gapin, J. I., Labban, J. D., Bohall, S. C., Wooten, J. S., \& Chang, Y. K. (2015). Acute exercise is associated with specific executive functions in college students with ADHD: A preliminary study. Journal of Sport and Health Science, 4(1), 89-96. https://doi.org/10.1016/j.jshs.2014.11.003

Geary, D. C., Hoard, M. K., Byrd-Craven, J., Nugent, L., \& Numtee, C. (2007). Cognitive mechanisms underlying achievement deficits in children with mathematical learning disability. Child Development, 78(4), 1343-1359. https://doi.org/10.1111/j.1467-8624.2007.01069.x

Gjervan, B., Torgersen, T., Nordahl, H. M., \& Rasmussen, K. (2012). Functional impairment and occupational outcome in adults with ADHD. Journal of Attention Disorders, 16(7), 544-552. https://doi.org/10.1177/1087054711413074

Goodwin, V. A., Richards, S. H., Taylor, R. S., Taylor, A. H., \& Campbell, J. L. (2008). The effectiveness of exercise interventions for people with Parkinson's disease: A systematic review and meta-analysis. Movement Disorders, 23(5), 631-640. https://doi.org/10.1002/mds.21922

Hagströmer, M., Oja, P., \& Sjöström, M. (2006). The International Physical Activity Questionnaire (IPAQ): a study of concurrent and construct validity. Public Health Nutrition, 9(6), 755-762. https://doi.org/10.1079/PHN2005898

Halperin, J. M., \& Healey, D. M. (2011). The influences of environmental enrichment, cognitive enhancement, and physical exercise on brain development: Can we alter the developmental trajectory of ADHD?. Neuroscience \& Biobehavioral Reviews, 35(3), 621-634. https://doi.org/10.1016/j.neubiorev.2010.07.006

Hasson, R., \& Fine, J. G. (2012). Gender differences among children with ADHD on continuous performance tests: a meta-analytic review. Journal of Attention Disorders, 16(3), 190-198. https://doi.org/10.1177/1087054711427398

Howard, A. L., Robinson, M., Smith, G. J., Ambrosini, G. L., Piek, J. P., \& Oddy, W. H. (2011). ADHD is associated with a "Western" dietary pattern in adolescents.

Journal of Attention Disorders, 15(5), 403-411.

https://doi.org/10.1177/1087054710365990 
Huang, Y. S., \& Tsai, M. H. (2011). Long-term outcomes with medications for attention-deficit hyperactivity disorder. CNS Drugs, 25(7), 539-554. https://doi.org/10.2165/11589380-000000000-00000

Jensen, P. S., Kettle, L., Roper, M. T., Sloan, M. T., Dulcan, M. K., Hoven, C., ... \& Payne, J. D. (1999). Are stimulants overprescribed? Treatment of ADHD in four US communities. Journal of the American Academy of Child \& Adolescent Psychiatry, 38(7), 797-804. https://doi.org/10.1097/00004583-199907000-00008

Ježová, D., Vigaš, M., Tatar, P., Kvetňanský, R., Nazar, K., Kaciuba-Uścilko, H., \& Kozlowski, S. (1985). Plasma testosterone and catecholamine responses to physical exercise of different intensities in men. European Journal of Applied Physiology and Occupational Physiology, 54(1), 62-66. https://doi.org/10.1007/BF00426300

Kalbag, A. S., \& Levin, F. R. (2005). Adult ADHD and substance abuse: diagnostic and treatment issues. Substance Use \& Misuse, 40(13-14), 1955-1981. https://doi.org/10.1080/10826080500294858

Klesges, L. M., Baranowski, T., Beech, B., Cullen, K., Murray, D. M., Rochon, J., \& Pratt, C. (2004). Social desirability bias in self-reported dietary, physical activity and weight concerns measures in 8-to 10-year-old African-American girls: results from the Girls Health Enrichment Multisite Studies (GEMS). Preventive Medicine, 38, 78-87. https://doi.org/10.1016/j.ypmed.2003.07.003

Kraemer, W. J., \& Ratamess, N. A. (2005). Hormonal responses and adaptations to resistance exercise and training. Sports Medicine, 35(4), 339-361. https://doi.org/10.2165/00007256-200535040-00004

Kramer, A. F., Erickson, K. I., \& Colcombe, S. J. (2006). Exercise, cognition, and the aging brain. Journal of Applied Physiology, 101(4), 1237-1242. https://doi.org/10.1152/japplphysiol.00500.2006

Kennedy, T. M., Howard, A. L., Mitchell, J. T., Hoza, B., Arnold, L. E., Hechtman, L. T., ... \& Molina, B. S. (2019). Adult substance use as a function of growth in peer use across adolescence and young adulthood in the context of ADHD: Findings from the MTA. Addictive Behaviors, 99, 106106. https://doi.org/10.1016/j.addbeh.2019.106106

Kessler, R. C., Adler, L., Ames, M., Demler, O., Faraone, S., Hiripi, E. V. A., ... \& Ustun, T. B. (2005). The World Health Organization Adult ADHD Self-Report Scale (ASRS): a short screening scale for use in the general population. Psychological Medicine, 35(2), 245. https://doi.org/10.1017/S0033291704002892 
Levy, F. (1993). Side effects of stimulant use. Journal of Paediatrics and Child Health, 29(4), 250-254. https://doi.org/10.1111/i.1440-1754.1993.tb00504.x

Lewandowski, L. J., Lovett, B. J., Codding, R. S., \& Gordon, M. (2008). Symptoms of ADHD and academic concerns in college students with and without ADHD diagnoses. Journal of Attention Disorders, 12(2), 156-161. https://doi.org/10.1177/1087054707310882

Liu-Ambrose, T., \& Donaldson, M. G. (2009). Exercise and cognition in older adults: is there a role for resistance training programmes?. British Journal of Sports Medicine, 43(1), 25-27. https://doi.org/10.1136/bjsm.2008.055616

Liu-Ambrose, T., Nagamatsu, L. S., Graf, P., Beattie, B. L., Ashe, M. C., \& Handy, T. C. (2010). Resistance training and executive functions: a 12-month randomized controlled trial. Archives of Internal Medicine, 170(2), 170-178. https://doi.org/10.1001/archinternmed.2009.494

Martel, M., Nikolas, M., \& Nigg, J. T. (2007). Executive function in adolescents with ADHD. Journal of the American Academy of Child \& Adolescent Psychiatry, 46(11), 1437-1444. https://doi.org/10.1097/chi.0b013e31814cf953

Mazzeo, R. S. (1991a). Catecholamine responses to acute and chronic exercise. Medicine and Science in Sports and Exercise, 23(7), 839-845.

Mazzeo, R. S., Bender, P. R., Brooks, G. A., Butterfield, G. E., Groves, B. M., Sutton, J. R., ... \& Reeves, J. T. (1991b). Arterial catecholamine responses during exercise with acute and chronic high-altitude exposure. American Journal of Physiology-Endocrinology And Metabolism, 261(4), E419-E424. https://doi.org/10.1152/aipendo.1991.261.4.E419

Medina, J. A., Netto, T. L., Muszkat, M., Medina, A. C., Botter, D., Orbetelli, R., ... \& Miranda, M. C. (2010). Exercise impact on sustained attention of ADHD children, methylphenidate effects. ADHD Attention Deficit and Hyperactivity

Disorders, 2(1), 49-58. https://doi.org/10.1007/s12402-009-0018-y

Mehren, A., Özyurt, J., Lam, A. P., Brandes, M., Müller, H. H., Thiel, C. M., \& Philipsen, A. (2019). Acute effects of aerobic exercise on executive function and attention in adult patients with ADHD. Frontiers in Psychiatry, 10, 132. https://doi.org/10.3389/fpsyt.2019.00132

Millstein, R. B., Wilens, T. E., Biederman, J., \& Spencer, T. J. (1997). Presenting ADHD symptoms and subtypes in clinically referred adults with ADHD. Journal of Attention Disorders, 2(3), 159-166. https://doi.org/10.1177/108705479700200302 
Michielsen, M., Comijs, H. C., Aartsen, M. J., Semeijn, E. J., Beekman, A. T., Deeg, D. J., \& Kooij, J. S. (2015). The relationships between ADHD and social functioning and participation in older adults in a population-based study. Journal of Attention Disorders, 19(5), 368-379. https://doi.org/10.1177/1087054713515748

Morton, W. A., \& Stockton, G. G. (2000). Methylphenidate abuse and psychiatric side effects. Primary care Companion to the Journal of Clinical Psychiatry, 2(5), 159. https://doi.org/10.4088/pcc.v02n0502

National Institute of Mental Health. (2017, November). Attention-Deficit/Hyperactivity Disorder (ADHD). National Institute of Mental Health. https://www.nimh.nih.gov/health/statistics/attention-deficit-hyperactivity-disorder -adhd

Neudecker, C., Mewes, N., Reimers, A. K., \& Woll, A. (2019). Exercise interventions in children and adolescents with ADHD: a systematic review. Journal of Attention Disorders, 23(4), 307-324. https://doi.org/10.1177/1087054715584053

Oades, R. D., Sadile, A. G., Sagvolden, T., Viggiano, D., Zuddas, A., Devoto, P., ... \& Russell, V. A. (2005). The control of responsiveness in ADHD by catecholamines: evidence for dopaminergic, noradrenergic and interactive roles. Developmental Science, 8(2), 122-131. https://doi.org/10.1111/j.1467-7687.2005.00399.x

Oosterlaan, J., Scheres, A., \& Sergeant, J. A. (2005). Which executive functioning deficits are associated with ADHD, ODD/CD and comorbid ADHD+ ODD/CD?. Journal of Abnormal Child Psychology, 33(1), 69-85. https://doi.org/10.1007/s10802-005-0935-y

Pan, C. Y., Tsai, C. L., Chu, C. H., Sung, M. C., Huang, C. Y., \& Ma, W. Y. (2019). Effects of physical exercise intervention on motor skills and executive functions in children with ADHD: A pilot study. Journal of Attention Disorders, 23(4), 384-397. https://doi.org/10.1177/1087054715569282

Piepmeier, A. T., Shih, C. H., Whedon, M., Williams, L. M., Davis, M. E., Henning, D. A., ... \& Etnier, J. L. (2015). The effect of acute exercise on cognitive performance in children with and without ADHD. Journal of Sport and Health Science, 4(1), 97-104. https://doi.org/10.1016/j.jshs.2014.11.004

Pliszka, S. R. (2005). The neuropsychopharmacology of attention-deficit/hyperactivity disorder. Biological Psychiatry, 57(11), 1385-1390. https://doi.org/10.1016/i.biopsych.2004.08.026

Polanczyk, G., De Lima, M. S., Horta, B. L., Biederman, J., \& Rohde, L. A. (2007). The worldwide prevalence of ADHD: a systematic review and metaregression 
analysis. American Journal of Psychiatry, 164(6), 942-948.

https://doi.org/10.1176/ajp.2007.164.6.942

Pontifex, M. B., Saliba, B. J., Raine, L. B., Picchietti, D. L., \& Hillman, C. H. (2013). Exercise improves behavioral, neurocognitive, and scholastic performance in children with attention-deficit/hyperactivity disorder. The Journal of Pediatrics, 162(3), 543-551. https://doi.org/10.1016/j.jpeds.2012.08.036

Pratley, R., Nicklas, B., Rubin, M., Miller, J., Smith, A., Smith, M., ... \& Goldberg, A. (1994). Strength training increases resting metabolic rate and norepinephrine levels in healthy 50-to 65-yr-old men. Journal of Applied Physiology, 76(1), 133-137. https://doi.org/10.1152/jappl.1994.76.1.133

Qualtrics (2019). (Version 07/2020) [Computer software]. https://www.qualtrics.com/

Rhodes, S. M., Coghill, D. R., \& Matthews, K. (2006). Acute neuropsychological effects of methylphenidate in stimulant drug-naïve boys with ADHD II-broader executive and non-executive domains. Journal of Child Psychology and Psychiatry, 47(11), 1184-1194. https://doi.org/10.1111/j.1469-7610.2006.01633.x

Rokeach, A., \& Wiener, J. (2018). The romantic relationships of adolescents with ADHD. Journal of Attention Disorders, 22(1), 35-45. https://doi.org/10.1177/1087054714538660

Sassenberg, K., \& Ditrich, L. (2019). Research in social psychology changed between 2011 and 2016: Larger sample sizes, more self-report measures, and more online studies. Advances in Methods and Practices in Psychological Science, 2(2), 107-114. https://doi.org/10.1177/2515245919838781

Semrud-Clikeman, M., Pliszka, S., \& Liotti, M. (2008). Executive functioning in children with attention-deficit/hyperactivity disorder: Combined type with and without a stimulant medication history. Neuropsychology, 22(3), 329. https://doi.org/10.1037/0894-4105.22.3.329

Strong, W. B., Malina, R. M., Blimkie, C. J., Daniels, S. R., Dishman, R. K., Gutin, B., ... $\&$ Rowland, T. (2005). Evidence based physical activity for school-age youth. The Journal of Pediatrics, 146(6), 732-737. https://doi.org/10.1016/j.jpeds.2005.01.055

Tantillo, M., Kesick, C. M., Hynd, G. W., \& Dishman, R. K. (2002). The effects of exercise on children with attention-deficit hyperactivity disorder. Medicine \& Science in Sports \& Exercise. https://doi.org/10.1097/00005768-200202000-00004 
Vaidya, C. J., Austin, G., Kirkorian, G., Ridlehuber, H. W., Desmond, J. E., Glover, G. H., \& Gabrieli, J. D. (1998). Selective effects of methylphenidate in attention deficit hyperactivity disorder: a functional magnetic resonance study. Proceedings of the National Academy of Sciences, 95(24), 14494-14499. https://doi.org/10.1073/pnas.95.24.14494

Van de Mortel, T. F. (2008). Faking it: social desirability response bias in self-report research. The Australian Journal of Advanced Nursing, 25(4), 40.

van Uffelen, J. G., Paw, M. J. C. A., Hopman-Rock, M., \& van Mechelen, W. (2008). The effects of exercise on cognition in older adults with and without cognitive decline: a systematic review. Clinical Journal of Sport Medicine, 18(6), 486-500. https://doi.org/10.1097/JSM.0b013e3181845f0b

Wehmeier, P. M., Schacht, A., \& Barkley, R. A. (2010). Social and emotional impairment in children and adolescents with ADHD and the impact on quality of life. Journal of Adolescent Health, 46(3), 209-217. https://doi.org/10.1016/j.jadohealth.2009.09.009

Widmar, N. J. O., Byrd, E. S., Dominick, S. R., Wolf, C. A., \& Acharya, L. (2016). Social desirability bias in reporting of holiday season healthfulness. Preventive Medicine Reports, 4, 270-276. https://doi.org/10.1016/i.pmedr.2016.06.017

Wigal, S. B., Nemet, D., Swanson, J. M., Regino, R., Trampush, J., Ziegler, M. G., \& Cooper, D. M. (2003). Catecholamine response to exercise in children with attention deficit hyperactivity disorder. Pediatric Research, 53(5), 756-761. https://doi.org/10.1203/01.PDR.0000061750.71168.23

Wigal, S. B., Emmerson, N., Gehricke, J. G., \& Galassetti, P. (2013). Exercise: applications to childhood ADHD. Journal of Attention Disorders, 17(4), 279-290. https://doi.org/10.1177/1087054712454192

Wilens, T. E., Biederman, J., Faraone, S. V., Martelon, M., Westerberg, D., \& Spencer, T. J. (2009). Presenting ADHD symptoms, subtypes, and comorbid disorders in clinically referred adults with ADHD. The Journal of Clinical Psychiatry, 70(11), 0-0. https://doi.org/10.4088/JCP.08m04785pur

Willcutt, E. G., Doyle, A. E., Nigg, J. T., Faraone, S. V., \& Pennington, B. F. (2005). Validity of the executive function theory of attention-deficit/hyperactivity disorder: a meta-analytic review. Biological Psychiatry, 57(11), 1336-1346. https://doi.org/10.1016/j.biopsych.2005.02.006

Williams, Penny, et al. "What Are the 3 Types of ADHD?" ADDitude, 20 Jan. 2020, www.additudemag.com/3-types-of-adhd/. 
Wilson, H. K., Cox, D. J., Merkel, R. L., Moore, M., \& Coghill, D. (2006). Effect of extended release stimulant-based medications on neuropsychological functioning among adolescents with attention-deficit/hyperactivity disorder. Archives of Clinical Neuropsychology, 21(8), 797-807. https://doi.org/10.1016/j.acn.2006.06.016

Yoon, M. C., Shin, M. S., Kim, T. S., Kim, B. K., Ko, I. G., Sung, Y. H., ... \& Kim, C. J. (2007). Treadmill exercise suppresses nigrostriatal dopaminergic neuronal loss in 6-hydroxydopamine-induced Parkinson's rats. Neuroscience Letters, 423(1), 12-17.9 https://doi.org/10.1016/j.neulet.2007.06.031

Young, S. (2005). Coping strategies used by adults with ADHD. Personality and Individual Differences, 38(4), 809-816. https://doi.org/10.1016/j.paid.2004.06.005 


\section{Appendices}

\section{Appendix A}

\section{Adult ADHD Self-Report Scale (ASRS-vI.I) Symptom Checklist}

\begin{tabular}{|c|c|c|c|c|c|}
\hline Patient Name & Today's Date & & \multirow[b]{2}{*}{ 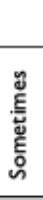 } & \multirow[b]{2}{*}{ 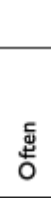 } & \multirow[b]{2}{*}{ 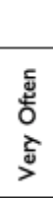 } \\
\hline $\begin{array}{l}\text { Please answer the } \\
\text { scale on the right } \\
\text { best describes how } \\
\text { this completed che } \\
\text { appointment. }\end{array}$ & 产 & 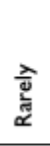 & & & \\
\hline $\begin{array}{l}\text { I. How often do you have trouble wrapping up the final details of a project, } \\
\text { once the challenging parts have been done? }\end{array}$ & & & & & \\
\hline $\begin{array}{l}\text { 2. How often do you have difficulty getting things in order when you have to do } \\
\text { a task that requires organization? }\end{array}$ & & & & & \\
\hline 3. How often do you have problems remembering appointments or obligations? & & & & & \\
\hline $\begin{array}{l}\text { 4. When you have a task that requires a lot of thought, how often do you avoid } \\
\text { or delay getting started? }\end{array}$ & & & & & \\
\hline $\begin{array}{l}\text { 5. How often do you fidget or squirm with your hands or feet when you have } \\
\text { to sit down for a long time? }\end{array}$ & & & & & \\
\hline $\begin{array}{l}\text { 6. How often do you feel overly active and compelled to do things, like you } \\
\text { were driven by a motor? }\end{array}$ & & & & & \\
\hline \multicolumn{6}{|c|}{ Part A } \\
\hline \multicolumn{6}{|c|}{$\begin{array}{l}\text { 7. How often do you make careless mistakes when you have to work on a boring or } \\
\text { difficult project? }\end{array}$} \\
\hline $\begin{array}{l}\text { 8. How often do you have difficulty keeping your attention when you are doing boring } \\
\text { or repetitive work? }\end{array}$ & & & & & \\
\hline $\begin{array}{l}\text { 9. How often do you have difficulty concentrating on what people say to you, } \\
\text { even when they are speaking to you directly? }\end{array}$ & & & & & \\
\hline 10. How often do you misplace or have difficulty finding things at home or at work? & & & & & \\
\hline II. How often are you distracted by activity or noise around you? & & & & & \\
\hline $\begin{array}{l}\text { 12. How often do you leave your seat in meetings or other situations in which } \\
\text { you are expected to remain seated? }\end{array}$ & & & & & \\
\hline 13. How often do you feel restless or fidgety? & & & & & \\
\hline $\begin{array}{l}\text { 14. How often do you have difficulty unwinding and relaxing when you have time } \\
\text { to yourself? }\end{array}$ & & & & & \\
\hline 15. How often do you find yourself talking too much when you are in social situations? & & & & & \\
\hline $\begin{array}{l}\text { 16. When you're in a conversation, how often do you find yourself finishing } \\
\text { the sentences of the people you are talking to, before they can finish } \\
\text { them themselves? }\end{array}$ & & & & & \\
\hline $\begin{array}{l}\text { 17. How often do you have difficulty waiting your turn in situations when } \\
\text { turn taking is required? }\end{array}$ & & & & & \\
\hline 18. How often do & & & & & \\
\hline
\end{tabular}


Appendix B

Modified International Physical Activity Questionnaire (IPAQ)

We are interested in finding out about the kinds of physical activities that people do as part of their everyday lives. The questions will ask you about the time you spent being physically active in the last 7 days. Please answer each question even if you do not consider yourself to be an active person. Please think about the activities you do at work, as part of your house and yard work, to get from place to place, and in your spare time for recreation, exercise or sport. Think about all the vigorous and moderate activities that you did in the last 7 days. Vigorous physical activities refer to activities that take hard physical effort and make you breathe much harder than normal. Moderate activities refer to activities that take moderate physical effort and make you breathe somewhat harder than normal.

\section{Start of Block: Part 1: Job-Related Physical Activity}

The first section is about your work. This includes paid jobs, farming, volunteer work, course work, and any other unpaid work that you did outside your home. Do not include unpaid work you might do around your home, like housework, yard work, general maintenance, and caring for your family. These are asked in Part 3.

PQ1 Do you currently have a job or do any undpaid work outside your home?

o Yes (1)

o No (2)

Skip To: End of Block If Do you currently have a job or do any unpaid work outside your home? $=$ No

The next questions are about all the physical activity you did in the last 7 days as part of your paid or unpaid work. This does not include traveling to and from work. 
PQ2 During the last 7 days, on how many days did you do vigorous physical activities like heavy lifting, digging, heavy construction, or climbing up stairs as part of your work? Think about only those physical activities that you did for at least 10 minutes at a time.

o Days per week: (1)

o No vigorous job-related physical activity (2)

Skip To: PQ4 If During the last 7 days, on how many days did you do vigorous physical activities like heavy lifti... $=$ No vigorous job-related physical activity

PQ3 How much time did you usually spend on one of those days doing vigorous physical activities as part of your work?

$\checkmark \quad$ Hours per day: (1)

$\square \quad$ Minutes per day: (2)

PQT1 As you spent time doing vigorous activities as part of your work, did you need/want to take breaks due to muscle fatigue or respiratory exhaustion?

- Yes, due to muscle fatigue (1)

- Yes, due to respiratory exhaustion (2)

$\square \quad$ No (4)

PQ4 Again, think about only those physical activities that you did for at least 10 minutes at a time. During the last 7 days, on how many days did you do moderate physical activities like carrying light loads as part of your work? Please do not include walking.

o Days per week (1)

o No moderate job-related physical activity (2) 
Skip To: PQ6 If Again, think about only those physical activities that you did for at least 10 minutes at a time.... $=$ No moderate job-related physical activity

PQ5 How much time did you usually spend on one of those days doing moderate physical activities as part of your work?

$\square \quad$ Hours per day (1)

$\square \quad$ Minutes per day (2)

PQT2 As you spent time doing moderate activities as part of your work, did you need/want to take breaks due to muscle fatigue or respiratory exhaustion?

$\square \quad$ Yes, due to muscle fatigue (1)

- Yes, due to respiratory exhaustion (2)

- $\quad$ No (4)

PQ6 During the last 7 days, on how many days did you walk for at least 10 minutes at a time as part of your work? Please do not count any walking you did to travel to or from work.

o Days per week (1)

o No job-related walking (2)

Skip To: End of Block If During the last 7 days, on how many days did you walk for at least 10 minutes at a time as part $0 . . .=$ No job-related walking

PQ7 How much time did you usually spend on one of those days walking as part of your work?

Hours per day (1)

$\square \quad$ Minutes per day (2) 
PQT3 As you spent time walking as part of your work, did you need/want to take breaks due to muscle fatigue or respiratory exhaustion?

$\square \quad$ Yes, due to muscle fatigue (1)

○ Yes, due to respiratory exhaustion (2)

ㄴ $\quad$ No (4)

Start of Block: Part 2: Transportation Physical Activity

These questions are about how you traveled from place to place, including to places like work, stores, movies, and so on.

PQ8 During the last 7 days, on how many days did you travel in a motor vehicle like a train, bus, car, or tram?

o Days per week (1)

o No traveling in a motor vehicle (2)

Skip To: QID89 If During the last 7 days, on how many days did you travel in a motor vehicle like a train, bus, car... = No traveling in a motor vehicle

PQ9 How much time did you usually spend on one of those days traveling in a train, bus, car, tram, or other kind of motor vehicle?

Hours per day (1)

Minutes per day (2)

Now think only about the bicycling and walking you might have done to travel to and from work, to do errands, or to go from place to place.

PQ10 During the last 7 days, on how many days did you bicycle for at least 10 minutes at a time to go from place to place?

o Days per week (1) 
o No bicycling from place to place (2)

Skip To: PQ12 If During the last 7 days, on how many days did you bicycle for at least 10 minutes at a time to go... = No bicycling from place to place

PQ11 How much time did you usually spend on one of those days to bicycle from place to place?

○ Hours per day (1)

- $\quad$ Minutes per day (2)

PQT4 On those days when you rode your bicycle from place to place did you need/want to take breaks from muscle fatigue or respiratory exhaustion?

- Yes, due to muscle fatigue (1)

○ Yes, due to respiratory exhaustion (2)

- No (4)

PQ12 During the last 7 days, on how many days did you walk for at least 10 minutes at a time to go from place to place?

o Days per week (1)

o No walking from place to place (2)

Skip To: End of Block If During the last 7 days, on how many days did you walk for at least 10 minutes at a time to go fro... = No walking from place to place

PQ13 How much time did you usually spend on one of those days walking from place to place?

Hours per day (1) 
- Minutes per day (2)

PQT5 On those days when you walked from place to place did you want/need to take breaks from muscle fatigue or respiratory exhaustion?

$\square \quad$ Yes, due to muscle fatigue (1)

○ Yes, due to respiratory exhaustion (2)

$\square \quad$ No (4)

DC3 For this question, please answer 10 minutes per day.

Hours per day (1)

Minutes per day (2)

Start of Block: Part 3: Housework, House Maintenance, and Caring for Family

This section is about some of the physical activities you might have done in the last 7 days in and around your home, like housework, gardening, yard work, general maintenance work, and caring for your family.

PQ14 Think about only those physical activities that you did for at least 10 minutes at a time. During the last 7 days, on how many days did you do vigorous physical activities like heavy lifting, chopping wood, shoveling snow, or digging in the garden or yard?

o Days per week (1)

o No vigorous activity in garden or yard (2)

Skip To: PQ16 If Think about only those physical activities that you did for at least 10 minutes at a time. During... = No vigorous activity in garden or yard

PQ15 How much time did you usually spend on one of those days doing vigorous physical activities in the garden or yard? 
$\square \quad$ Hours per day (1)

- Minutes per day (2)

PQT6 On those days when you completed physical activities in the yard, did you want/need to take breaks from muscle fatigue or respiratory exhaustion?

○ Yes, due to muscle fatigue (1)

○ Yes, due to respiratory exhaustion (2)

두 (4)

PQ16 Again, think about only those physical activities that you did for at least 10 minutes at a time. During the last 7 days, on how many days did you do moderate activities like carrying light loads, sweeping, washing windows, and raking in the garden or yard?

o Days per week (1)

o No moderate activity in garden or yard (2)

Skip To: PQ18 If Again, think about only those physical activities that you did for at least 10 minutes at a time.... = No moderate activity in garden or yard

PQ17 How much time did you usually spend on one of those days doing moderate physical activities in the garden or yard?

o Hours per day (1)

o Minutes per day (2)

o Click to write Choice 3 (3)

PQT7 On those days when you completed moderate physical activities in the yard, did you want/need to take breaks from muscle fatigue or respiratory exhaustion?

o Yes, due to muscle fatigue (1)

o Yes, due to respiratory exhaustion (2) 


\section{o No (3)}

PQ18 Once again, think about only those physical activities that you did for at least 10 minutes at a time. During the last 7 days, on how many days did you do moderate activities like carrying light loads, washing windows, scrubbing floors and sweeping inside your home?

o Days per week (1)

o No moderate activity inside home (2)

Skip To: End of Block If Once again, think about only those physical activities that you did for at least 10 minutes at a... = No moderate activity inside home

PQ19 How much time did you usually spend on one of those days doing moderate physical activities inside your home?

$\square \quad$ Hours per day (1)

$\square \quad$ Minutes per day (2)

PQT8 On those days when you completed moderate physical activities in your home did you want/need to take breaks from muscle fatigue or respiratory exhaustion?

$\square \quad$ Yes, due to muscle fatigue (1)

- Yes, due to respiratory exhaustion (2)

$\square \quad$ No (4)

Start of Block: Part 4: Recreation, Sport, and Leisure-Time

This section is about all the physical activities that you did in the last 7 days solely for recreation, sport, exercise or leisure. Please do not include any activities you have already mentioned.

PQ20 Not counting any walking you have already mentioned, during the last 7 days, on how many days did you walk for at least 10 minutes at a time in your leisure time? 
o Days per week (1)

o No walking in leisure time (2)

Skip To: PQ22 If Not counting any walking you have already mentioned, during the last 7 days, on how many days did... = No walking in leisure time

PQ21 How much time did you usually spend on one of those days walking in your leisure time?

○ Hours per day (1)

$\square \quad$ Minutes per day (2)

PQT9 On those days when you walked in your leisure time did you want/need to take breaks from muscle fatigue or respiratory exhaustion?

○ Yes, due to muscle fatigue (1)

○ Yes, due to respiratory exhaustion (2)

- No (4)

DC4 For this question, please answer 2 hours.

$\square \quad$ Hours per day (1)

- $\quad$ Minutes per day (2)

PQ22 Think about only those physical activities that you did for at least 10 minutes at a time. During the last 7 days, on how many days did you do vigorous physical activities like aerobics, running, fast bicycling, or fast swimming in your leisure time?

o Days per week (1)

o No vigorous activity in leisure time (2) 
Skip To: PQ24 If Think about only those physical activities that you did for at least 10 minutes at a time. During... $=$ No vigorous activity in leisure time

PQ23 How much time did you usually spend on one of those days doing vigorous physical activities in your leisure time?

Hours per day (1)

$\square \quad$ Minutes per day (2)

PQT10 On those days when you completed vigorous physical activities like aerobics, running, fast bicycling, or fast swimming in your leisure time did you want/need to take breaks from muscle fatigue or respiratory exhaustion?

- Yes, due to muscle fatigue (1)

- Yes, due to respiratory exhaustion (2)

$\square \quad$ No (4)

PQ24 Again, think about only those physical activities that you did for at least 10 minutes at a time. During the last 7 days, on how many days did you do moderate physical activities like bicycling at a regular pace, swimming at a regular pace, and doubles tennis in your leisure time?

o Days per week (1)

o No moderate activity in leisure time (2)

Skip To: End of Block If Again, think about only those physical activities that you did for at least 10 minutes at a time.... = No moderate activity in leisure time

PQ25 How much time did you usually spend on one of those days doing moderate physical activities in your leisure time?

$\square \quad$ Hours per day (1) 
PQT11 On those days when you completed moderate physical activities like like bicycling at a regular pace, swimming at a regular pace, and doubles tennis in your leisure time, did you want/need to take breaks from muscle fatigue or respiratory exhaustion?

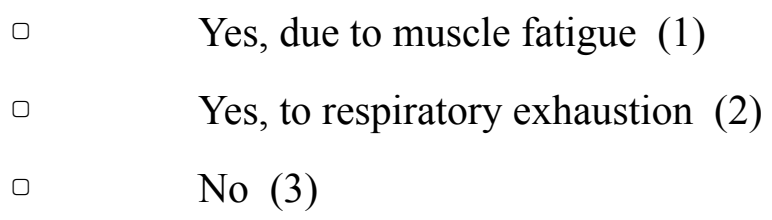

\section{Start of Block: Part 5: Time Spent Sitting}

The last questions are about the time you spend sitting while at work, at home, while doing course work and during leisure time. This may include time spent sitting at a desk, visiting friends, reading or sitting or lying down to watch television. Do not include any time spent sitting in a motor vehicle that you have already told me about.

PQ26 During the last 7 days, how much time did you usually spend sitting on a weekday?

$\square \quad$ Hours per day (1)

$\square \quad$ Minutes per day (2)

PQ27 During the last 7 days, how much time did you usually spend sitting on a weekend day?

$\square \quad$ Hours per day (1)

$\square \quad$ Minutes per day (2) 